\title{
Determination of effective medicinal components in Lonicera macranthoides flower buds
}

\author{
Jing Cai ${ }^{1}$, Xinyang Zhang ${ }^{1}$, Huan Dai ${ }^{1}$ \\ ${ }^{1}$ Wuhan Institute of Design and Sciences, Wuhan 430205
}

\begin{abstract}
This study is to determination of active medicinal components in Lonicera macranthoides. The results of High-performance liquid chromatography showed that the contents of chlorogenic acid were as follows: Baiyun: $6.297 \%$, jincuilei: $5.293 \%$, yincuilei: $5.288 \%$, common variety: $7.455 \%$, common variety (after flowering) : $4.140 \%$. The contents of Luteolin in different Lonicera macranthoides varieties were as follows: Baiyun: $0.0264 \%$; Jincuilei: $0.0573 \%$; Yincuilei: $0.0347 \%$; common variety: $0.0394 \%$; common variety (after flowering) : $0.0197 \%$.
\end{abstract}

\section{Introduction}

In the 2005 edition of the Chinese Pharmacopoeia, one of the bases for distinguishing flos Lonicerae from Flos Lonicerae japonicae was "analysis of chemical constituents, the active constituents of Flos Lonicerae are mainly Luteolin glycosides, but the other varieties contain little chlorogenic acid, there have also been a number of reports in recent years of differences in the contents of Lonicera Japonica and honeysuckle, in order to further determine the market value of Lonicera macranthoides, in this experiment, the contents of Luteolin and chlorogenic acid in the flower buds of Lonicera macranthoides were determined[1-2]. Chlorogenic acid, alias: Chlorogenic acid, CAFFEIC tannic acid, 3-caffeoylquinic acid, formula:C16H18O9.

Luteoloside (English name: Luteoloside, alias name: luteolin-7-O-glucoside); Cynaroside, molecular formula: $\mathrm{C}_{21} \mathrm{H}_{20} \mathrm{O} 11[3]$.

\section{Materials and methods}

\subsection{Experimental materials and apparatus}

\subsubsection{Experimental materials}

This experimental material is Lonicera macranthoides dry flower bud, from Hunan Longhui honeysuckle science and technology development center. The four common varieties are Jincuilei, Yincuilei, Baiyun and Longhui (before and after flowering). The control samples, chlorogenic acid (batch number: 110753-200413) and Luteolin (batch number: 111720-201106; 99.3\%) were all from China Institute of Pharmaceutical and biological products.

\subsubsection{Equipment and chromatographic conditions}

P230IIhigh-pressure constant-current pump; UV230IIultraviolet-visible detector; Zwii Column Incubator; EC2006 Data Chromatographic Workstation; Diamonsil C18 column. Octadecyl Silane Bonded Silica Gel was used as Filler, acetonitrile (a)- $0.1 \%$ phosphoric acid solution (b) was used as mobile phase gradient elution:

Table1. Gradient elution program

\begin{tabular}{|c|c|c|}
\hline Time(min) & Mobile phase A (\%) & Mobile phase B(\%) \\
\hline $0 \rightarrow 5$ & 14 & 86 \\
\hline $5 \rightarrow 15$ & $14 \rightarrow 28$ & $86 \rightarrow 72$ \\
\hline $15 \rightarrow 27$ & $28 \rightarrow 25$ & $72 \rightarrow 75$ \\
\hline $27 \rightarrow 30$ & $25 \rightarrow 14$ & $75 \rightarrow 86$ \\
\hline
\end{tabular}

The flow rate of the mobile phase was $1.0 \mathrm{Ml} / \mathrm{min}$, the column temperature was $30^{\circ} \mathrm{c}$, the detection wavelength was $327 \mathrm{~nm}$ (0-12 Min) , $350 \mathrm{~nm}$ (12-30 Min) and the injection volume was $10 \mu \mathrm{l}$.

\subsection{Assay}

\subsubsection{Preparation of Reference Solution}

This experiment take $19.10 \mathrm{mg}$ of chlorogenic acid reference substance, put it in a brown measuring flask, add $50 \%$ methanol to make $0.382 \mathrm{mg} / \mathrm{ml}, 0.0382 \mathrm{mg} / \mathrm{ml}$ solution, that is (stored below $10^{\circ} \mathrm{C}$ ). Take $10.58 \mathrm{mg}$ of luteolin reference substance, add 50\% methanol to make $0.01 \mathrm{mg} / \mathrm{ml}, 0.001 \mathrm{mg} / \mathrm{ml}$ solution, that is (stored below $\left.4^{\circ} \mathrm{C}\right)$.

\footnotetext{
* Corresponding author: Jing Cai email: 84016963@qq. com
} 


\subsubsection{Preparation of Test Solution}

This experiment take about $0.5 \mathrm{~g}$ of this product powder (passed through the No. 4 sieve), accurately weigh it, place it in a stoppered conical flask, add $50 \%$ methanol $50 \mathrm{ml}$ accurately, weigh it, and ultrasonically treat it (power $250 \mathrm{~W}$, frequency $30 \mathrm{kHz}$ ) for 30 minutes. Let it cool and weigh it again. Use $50 \%$ methanol to make up the lost weight. Shake well and filter. Accurately measure $5 \mathrm{ml}$ of the filtrate and place it in a $25 \mathrm{ml}$ brown measuring flask. Add $50 \%$ methanol to the mark and shake well to get it.

\subsubsection{Investigation of linear relationship}

In this experiment, precisely aspirate $0.0382 \mathrm{mg} / \mathrm{ml}$ chlorogenic acid reference substance $1 \mu \mathrm{l}, 3 \mu \mathrm{l}$, $0.382 \mathrm{mg} / \mathrm{ml}$ chlorogenic acid reference substance $2 \mu 1,5 \mu 1$, $8 \mu \mathrm{l}, 13 \mu \mathrm{l}, 18 \mu \mathrm{l}, 26 \mu \mathrm{l}, 28 \mu \mathrm{l}$, respectively according to the chromatographic conditions, and use the reference substance to inject samples The amount $(\mu \mathrm{g})$ is the abscissa and the corresponding peak area is the ordinate to obtain the standard curve of chlorogenic acid.

In the meantime, Precisely draw $0.001050594 \mathrm{mg} / \mathrm{ml}$ luteolin reference substance $1 \mu \mathrm{l}, 8 \mu \mathrm{l}, 12 \mu \mathrm{l}, 16 \mu \mathrm{l}$, $0.01050594 \mathrm{mg} / \mathrm{ml}$ luteolin reference substance $4 \mu \mathrm{l}, 5 \mu \mathrm{l}$, $8 \mu \mathrm{l}, 10 \mu \mathrm{l}, 12 \mu \mathrm{l}, 16 \mu \mathrm{l}, 20 \mu \mathrm{l}, 25 \mu \mathrm{l}, 30 \mu \mathrm{l}$, respectively according to the chromatographic conditions For sample injection, take the injection amount of the reference substance $(\mu \mathrm{g})$ as the abscissa and the corresponding peak area as the ordinate to obtain the standard curve of luteolin.

\subsubsection{Precision test}

In this test, Precisely draw $10 \mu$ of the same test solution and repeat the injection 6 times to obtain the RSD of the peak area of chlorogenic acid and luteolin.

\subsubsection{Stability Test}

In this test, at $0 \mathrm{~h}, 3 \mathrm{~h}, 6 \mathrm{~h}, 9 \mathrm{~h}, 12 \mathrm{~h}, 15 \mathrm{~h}$ and $1 \mathrm{~d}, 2 \mathrm{~d}, 3$ $\mathrm{d}, 4 \mathrm{~d}$, and $5 \mathrm{~d}$ after the preparation of the test product, $10 \mu 1$ of the test product solution was precisely drawn into the sample. Calculate the RSD of the peak area of chlorogenic acid and luteolin.

\subsubsection{RepeatabilityTest}

In this test, take the same sample, accurately weigh 6 parts, prepare the sample solution according to the method, inject the sample according to the chromatographic conditions, determine the content of chlorogenic acid and luteolin, and obtain the RSD of the peak area of chlorogenic acid and luteolin.

\subsubsection{Sample recovery test}

In this test, take $0.5 \mathrm{~g}$ of the same sample powder of Lonicera japonica, 6 parts, accurately weighed, and accurately add $1 \mathrm{ml}$ of reference substance chlorogenic acid $(1.0 \mathrm{mg} / \mathrm{ml})$ and $2 \mathrm{ml}$ of luteolin $(0.1 \mathrm{mg} / \mathrm{ml})$ respectively, and prepare according to the method. The test solution was tested for content, and the average recovery rate of chlorogenic acid and luteolin was calculated.

\subsubsection{Determination of sample content}

The prepared test solution was subjected to gradient elution according to the gradient elution procedure in Table 1, and then the content of the sample was calculated according to the linear regression equation of the peak area of the sample and the corresponding reference substance.

\section{Results and analysis}

\subsection{Investigation results of linear relationship}

Chlorogenic acid-linear relationship investigation: According to the system adaptability test method, enter the chlorogenic acid reference substance of different concentrations, and then calculate the linear correlation number of chlorogenic acid. The regression equation is: $\mathrm{y}$ $=2482.2219 \mathrm{x}+164.7491 ; \mathrm{r}=0.9999$, and the linear range is $0.0382 \sim 10.696 \mu \mathrm{g}$.

Table2. Analysis of linear relationship on chlorogenic acid and luteolin glycosides

\begin{tabular}{|c|c|c|c|c|c|}
\hline $\begin{array}{c}\text { Chlorogenic-acid } \\
\text { injection volume } \\
(\mathbf{u l})\end{array}$ & $\begin{array}{c}\text { Injection } \\
\text { volume }\end{array}$ & Peak area & $\begin{array}{c}\text { Luteolin injection } \\
\text { volume (ul) }\end{array}$ & Injection volume & Peak area \\
\hline 0.1 & 0.0382 & 104.11 & 0.1 & 0.001050594 & 2.67 \\
\hline 0.3 & 0.1146 & 307.69 & 0.8 & 0.008404752 & 20.56 \\
\hline 2 & 0.764 & 2041.21 & 1.2 & 0.012607128 & 30.62 \\
\hline 5 & 1.91 & 4977.65 & 1.6 & 0.016809504 & 41.71 \\
\hline 8 & 3.056 & 7945.76 & 4.0 & 0.042023760 & 106.28 \\
\hline 13 & 4.966 & 12609.52 & 5.0 & 0.052529700 & 132.38 \\
\hline 18 & 6.876 & 17424.46 & 8.0 & 0.084047520 & 212.21 \\
\hline 26 & 9.932 & 24581.39 & 10 & 0.105059400 & 262.70 \\
\hline 28 & 10.696 & 26691.11 & 12 & 0.126071280 & 312.44 \\
\hline & & & 16 & 0.168095040 & 433.58 \\
& & & 20 & 0.210118800 & 535.19 \\
\hline
\end{tabular}


Investigation of luteolin-linear relationship: According to the system adaptability test method, different concentrations of luteolin reference substance were added, and then the linear correlation number of luteolin was calculated. The regression equation is: $\mathrm{y}=2565.4213 \mathrm{x}-2.4465 ; \mathrm{r}=0.9999$, and the linear range is $0.001050594 \sim 0.3151782 \mu \mathrm{g}$.

The linear relationship investigation results show that the linear relationship between chlorogenic acid and luteolin is good.

\subsection{Precision test results}

Precisely draw $10 \mathrm{uL}$ of the same test solution and repeat the injection 6 times. The results are shown in Table 3 . The RSD of the peak areas of chlorogenic acid and luteolin were $0.3 \%$ and $2.1 \%$, respectively. It shows that the precision of the detection method in this experiment is good.

Table3. Precision results

\begin{tabular}{|c|c|c|}
\hline & Chlorogenic acid peak area & Luteolin peak area \\
\hline & 3242.12 & 15.08 \\
\hline & 3249.38 & 14.36 \\
\hline & 3265.84 & 14.25 \\
\hline & 3261.25 & 14.52 \\
\hline & 3262.95 & 14.85 \\
\hline RSD & 3265.68 & 14.55 \\
\hline & 0.00301339 & 0.021260992 \\
\hline
\end{tabular}

\subsection{Stability test results}

At $0,3,6,9,12,15 \mathrm{~h}$ and $1,2,3,4$, and 5 days after the preparation of the test product, $10 \mathrm{uL}$ of the test product solution was precisely drawn and injected. The results are shown in Table 4. The intraday RSDs of the peak areas of chlorogenic acid and luteolin were $0.3 \%$ and $2.0 \%$, respectively; the RSDs of the peak areas of chlorogenic acid and luteolin during the day were $0.4 \%$ and $2.1 \%$, respectively. It shows that the stability of the test product during the test is good.

Table4. Stability Test Results

\begin{tabular}{|c|c|c|c|c|c|}
\hline Time & $\begin{array}{c}\text { Chlorogenic acid peak } \\
\text { area }\end{array}$ & Luteolin peak area & Time & $\begin{array}{c}\text { Chlorogenic } \\
\text { acid peak area }\end{array}$ & $\begin{array}{c}\text { Luteolin peak } \\
\text { area }\end{array}$ \\
\hline $0 \mathrm{~h}$ & 3265.68 & 15.09 & $1 \mathrm{~d}$ & 3245.68 & 14.95 \\
\hline $3 \mathrm{~h}$ & 3249.38 & 14.76 & $2 \mathrm{~d}$ & 3248.26 & 14.56 \\
\hline $6 \mathrm{~h}$ & 3265.84 & 14.56 & $3 \mathrm{~d}$ & 3255.84 & 14.25 \\
\hline $9 \mathrm{~h}$ & 3261.25 & 14.52 & $4 \mathrm{~d}$ & 3251.25 & 14.31 \\
\hline $12 \mathrm{~h}$ & 3262.95 & 14.5 & $5 \mathrm{~d}$ & 3220.95 & 14.25 \\
\hline $15 \mathrm{~h}$ & 3240.06 & 14.22 & $\mathrm{RSD}$ & 0.00420428 & 0.020761881 \\
\hline $\mathrm{RSD}$ & 0.003220575 & 0.020020526 & & & \\
\hline
\end{tabular}

\subsection{Repeatability test results}

Take the same sample, accurately weigh 6 parts, and prepare the sample solution. The results are shown in Table 4-5: The RSD of chlorogenic acid and luteolin were determined to be $1.4 \%$ and $3.8 \%$, respectively, indicating that the experimental method has good repeatability.
Table5. Repeatability Test Results

\begin{tabular}{|c|c|c|}
\hline $\begin{array}{c}\text { Sample } \\
\text { weight }\end{array}$ & $\begin{array}{c}\text { Luteolin peak } \\
\text { area }\end{array}$ & $\begin{array}{c}\text { Luteolin peak } \\
\text { area }\end{array}$ \\
\hline 0.5067 & 3487.07 & 15.58 \\
\hline 0.4917 & 3384.82 & 14.36 \\
\hline 0.4964 & 3416.94 & 14.25 \\
\hline 0.5049 & 3475.02 & 14.52 \\
\hline
\end{tabular}




\begin{tabular}{|l|l|l|}
\hline 0.4760 & 3276.91 & 14.85 \\
\hline 0.4696 & 3232.17 & 14.55 \\
\hline 0.4835 & 3327.76 & 15.08 \\
\hline
\end{tabular}

\subsection{Sample recovery rate}

Take $0.5 \mathrm{~g}$ of the same gray felt honeysuckle sample powder, 6 parts, accurately weighed, and accurately add 5 $\mathrm{mL}$ of the reference substance chlorogenic acid $(0.382 \mathrm{mg} / \mathrm{mL})$ respectively, and prepare the test solution according to the method under the item, and carry out the content determination and calculation The average recovery rate of chlorogenic acid was $98.3 \%$, and the RSD was $0.37 \%$.

Table6. Sample recovery Test Results

\begin{tabular}{|c|c|c|}
\hline Sample weight & Luteolin peak area & $\begin{array}{c}\text { Recoveries } \\
(\mathbf{\%})\end{array}$ \\
\hline 0.5014 & 5330.34 & 100.12 \\
\hline 0.4987 & 5301.30 & 99.78 \\
\hline 0.4998 & 5312.88 & 98.98 \\
\hline 0.5087 & 5407.60 & 100.09 \\
\hline 0.4887 & 5195.01 & 101.12 \\
\hline 0.5167 & 5492.64 & 99.99 \\
\hline
\end{tabular}

\subsection{Results of sample content determination}

Prepare the test solution of each sample according to the method below, inject the sample according to the chromatographic conditions below, measure each sample 3 times, record the chromatogram and calculate the peak area according to the external standard method. The content of chlorogenic acid and luteolin in 5 different origins of Lonicera japonica is shown in Tables 7 and 8 . The HPLC diagrams of the reference substance and the sample solution are shown in the figure below. The results of high performance liquid chromatography showed that the chlorogenic acid content of each Lonicera japonica varieties were as follows: Baiyun: 6.297\%, RSD0.0137; Jin Cui Lei: 5.293\%, RSD 0.0060; Yin Cui Lei: 5.288\%, RSD 0.0029; common species : 7.455\%, RSD0.0065; common species (after flowering): $4.140 \%$, RSD0.0151. The content of luteolin in each Lonicera japonica variety is as follows, Baiyun: 0.0264\%, RSD 0.0079; Jin Cui Lei: $0.0573 \%$, RSD 0.0053; Yin Cui Lei: $0.0347 \%$, RSD 0.0010; Common species: $0.0394 \%$, RSD 0. 0073; common varieties (after flowering): $0.0197 \%$, RSD0.0031.

Table7. Content of chlorogenic acid in different species

\begin{tabular}{|c|c|c|}
\hline Species & Chlorogenic acid (\%) & RSD \\
\hline Baiyun & 6.297 & 0.0137 \\
\hline Jin Cuilei & 5.293 & 0.0060 \\
\hline Silver Cuilei & 5.288 & 0.0029 \\
\hline Common species & 7.455 & 0.0065 \\
\hline $\begin{array}{c}\text { Common species } \\
\text { (after flowering) }\end{array}$ & 4.410 & 0.0151 \\
\hline
\end{tabular}

Table8. Content of Luteoloside in different species

\begin{tabular}{|c|c|c|}
\hline Species & Luteoloside (\%) & RSD \\
\hline Baiyun & 0.0264 & 0.0079 \\
\hline Jin Cuilei & 0.0573 & 0.0053 \\
\hline Silver Cuilei & 0.0347 & 0.0010 \\
\hline Common species & 0.0394 & 0.0073 \\
\hline $\begin{array}{c}\text { Common species } \\
\text { (after flowering) }\end{array}$ & 0.0197 & 0.0031 \\
\hline
\end{tabular}

\section{Conclusion and discussion}

The results of this experiment show that the chlorogenic acid content of the flower buds of Lonicera japonica is far higher than that required for genuine honeysuckle. However, the content of luteolin is not as good as that of genuine honeysuckle. However, chlorogenic acid and luteolin have their own different pharmaceutical values[45].

The dry processing technology of honeysuckle flower buds directly affects the content of chlorogenic acid and luteolin in the flower buds. At present, the drying processing techniques used for the flower buds of the gray felt hair honeysuckle include sun drying, drying, shade drying and fumigation[6]. Comparing the effects of sun drying, shade drying, steaming and sulfur fumigation on the content of chlorogenic acid in Lonicera japonica, the results show that the content of chlorogenic acid in the shade drying is the highest. Compared with the other three methods, there are extremely significant differences. The sulfur fumigation method Second, but it is also significantly better than steaming and direct drying. The content of chlorogenic acid in honeysuckle dried by sun drying is the lowest. The sun-drying is divided into steaming, fumigating, frying, and raw drying. Studies have shown that steaming and fumigation are better, while the content of chlorogenic acid and luteolin is lower in raw sun-dried products. Studies have shown that honeysuckle produced by sulfur fumigation and drying methods not only has good appearance quality, but also has high chlorogenic acid content.

The samples in this experiment are divided into two drying methods, one is drying and the other is drying. The results showed that the raw sun exposure method greatly reduced the content of the effective ingredients in the flower buds of Lonicera japonica. Moreover, the dried flower buds are obviously darker, which also affects the appearance quality. The dried flower buds are green in appearance and good in quality.

\section{Author}

* Corresponding author: Jing Cai (1986-), female, from Macheng, Hubei Province, lecturer, email: 84016963@qq. com, Research Direction: Utilization of GERMPLASM resources and its research. 


\section{Acknowledgments}

This research was financially supported by the Provincial Teaching Research Project (2018496), (2017505); Scientific Research Project of Wuhan Institute of Design and Engineering (K201905) ; Wuhan Institute of Design and Engineering, school-level quality courses (2017 YK1116).

\section{References}

1. Yan Chen. Determination of chlorogenic acid in processed products of Lonicera macranthoides by HPLC. Identification of Flos Lonicerae, Flos LONICERAE and Flos LONICERAE. 2011, (31)2324

2. Xugang Sun . Electronic Journal of Clinical Medical Literature. Determination of chlorogenic acid in zipu tongfeng mixture by 2018(a 4)

3. Sha Yang.Determination of Luteolin, chlorogenic acid and their adulterants in honeysuckle granules by HPLC.Hwaseo Journal of Pharmacy. 2021,36(01)

4. Zhongjun Liu .Determination of chlorogenic acid in Zipu tongfeng mixture by HPLC.Hwaseo Journal of Pharmacy. 2016(06)

5. Feiyan $\mathrm{Wu}$, Jianguo Zeng. Identification and identification of Lonicera Japonica and Lonicera Japonica [ j ] .Chinese herbal medicine. 2014(08)

6. Jinhua Zhu. Simultaneous determination of nine active components in leaves of Lonicera Japonica thunb by HPLC.Chemical Research. 2017(01) 